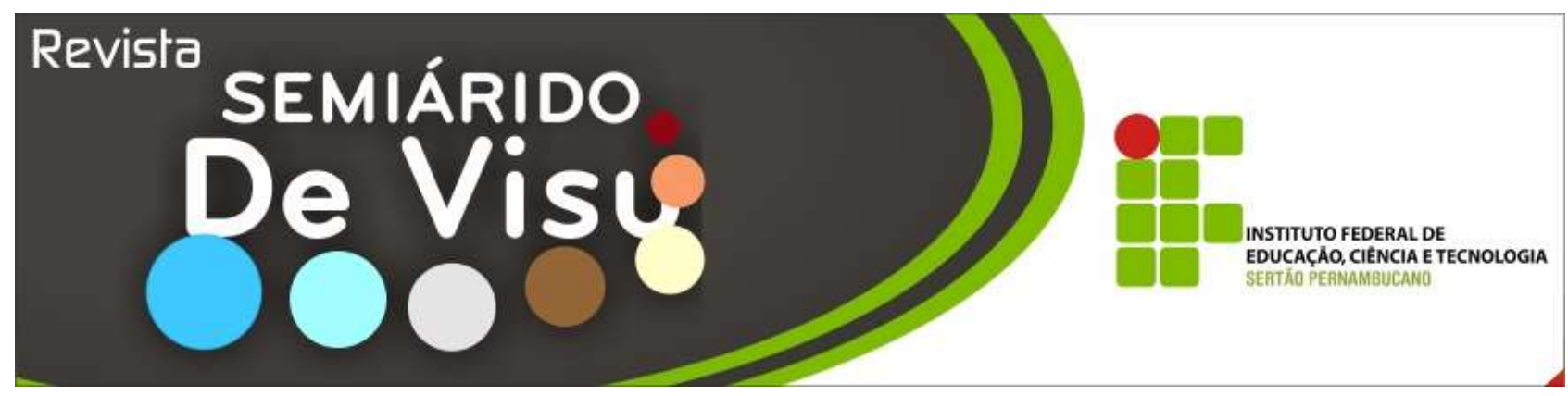

\title{
Diagnóstico dos Resíduos de Construção e Demolição da Cidade de
}

\section{Salgueiro/Pernambuco}

\author{
Maria do Socorro Bezerra Sá1, Vinicius Gonçalves Torres Cavalcante² Camila Macêdo Medeiros $^{3}$ \\ Eduardo da Cruz Teixeira ${ }^{4}$ \\ 1,2, Discentes do Curso Médio Integrado ao Técnico em Edificações do Instituto Federal do Sertão Pernambucano, IFSPE campus \\ Salgueiro, Rodovia BR 232,Km508 sentido Recife, Zona Rural, Salgueiro/PE, CEP 56.000-000/ Telefone: (87) 3421.0050 / \\ E-mail: ${ }^{1}$ m.socorro97@ hotmail.com; ${ }^{2}$ vinicius-cabrobo@ hotmail.com. \\ 3,4, Docentes do Curso Médio Integrado ao Técnico em Edificações do Instituto Federal do Sertão Pernambucano, IFSPE campus \\ Salgueiro, Rodovia BR 232,Km508 sentido Recife, Zona Rural, Salgueiro/PE, CEP 56.000-000/ Telefone: (87) 3421.0050 / \\ E-mail: ${ }^{3}$ camila.medeiros@ ifsertao-pe.edu.br, ${ }^{4}$ eduardo.teix eira@ @ifsertao-pe.edu.br
}

\begin{abstract}
RESUMO: A construção civil vem crescendo aceleradamente no país nos últimos anos. Em Salgueiro-PE essa realidade é visível, visto que, situada no sertão central e cortada pelas principais vias do nordeste, acolhe hoje duas grandes obras do governo federal: a Transnordestina e a Transposição do Rio São Francisco. Também recebeu o Instituto Federal de Educação, Ciência e Tecnologia do Sertão Pernambucano, Campus Salgueiro, como fonte de qualificação profissional, a construção do Shopping da cidade, além de programas do governo, como o Minha Casa, Minha Vida, com essas obras vem também o aumento da geração de Resíduos da Construção e Demolição. Diante disso, este trabalho busca fazer um levantamento inicial das quantidades de resíduos provenientes da construção civil na cidade de Salgueiro-PE em construções de médio porte, de forma que se possa avaliar os tipos de resíduos produzidos no canteiro de obras e quantificá-los com base na resolução do Conselho Nacional do Meio Ambiente-CONAMA, que aborda as diretrizes para a efetiva redução dos impactos ambientais gerados pelos resíduos oriundos da construção civil.
\end{abstract}

Palavras-chave: Crescimento do município, Materiais de construção, Sustentabilidade

\section{Diagnosis of Construction Waste and Demolition City Salgueiro/Pernambuco}

\begin{abstract}
The construction industry has been growing rapidly in the country in recent years. Salgueiro-PE that reality is visible, as, located in the central hinterland and cut the main roads northeast, welcomes today two major works of the federal government: Transnordestina and Rio Transposition of San Francisco. Also received the Federal Institute of Education, Science and Technology Pernambucano Hinterland, Campus Salgueiro as a source of professional qualification, the construction of the city's shopping, and government programs such as Minha Casa, Minha Vida, with these works is also increasing generation of waste from construction and demolition. Thus, this paper aims to make an initial survey of the amounts of waste from the construction in the city of Salgueiro-PE in medium-sized buildings, so that it can evaluate the types of waste produced in the construction site and to quantify them based on the resolution of the National Environment Council, CONAMA, which discusses the guidelines for the effective reduction of environmental impacts caused by waste from construction.
\end{abstract}

Keywords: city growth, building materials, Sustainability 
(SÁ et al., 2015)

\section{Introdução}

A construção civil vem crescendo aceleradamente no país nos últimos anos. Em Salgueiro-PE essa realidade é visível, visto que, situada no sertão central é cortada pelas principais vias do nordeste, acolhe hoje duas grandes obras do governo federal: a Transnordestina e a Transposição do Rio São Francisco. Também recebeu o Instituto Federal de Educação, Ciência e Tecnologia do Sertão Pernambucano, Campus Salgueiro, como fonte de qualificação profissional, a construção do Shopping da cidade, além de programas do governo, como o Minha Casa, Minha Vida.

Esses aspectos contribuem para o crescimento populacional, do comércio e, consequentemente, habitacional da cidade. A Revista Zum (2013) afirmou que a pequena Salgueiro (PE) se tornou o novo centro de irradiação de importantes eixos de infraestrutura do país, como a Ferrovia Transnordestina e o canal de Transposição do Rio São Francisco. Uma forte evidência desse crescimento é que a cidade, chamada de "Balcão do Desenvolvimento", teve um crescimento de $88 \%$ no número de Microempreendedores Individuais no período de um ano, de 2012 a 2013 (Prefeitura de Salgueiro, 2013).

Com o crescimento econômico e habitacional, cresce junto o setor da construção civil. Esse fator, embora positivo do ponto de vista econômico, pode ser preocupante caso não haja uma preocupação ambiental com o resíduos gerados nas construções.

Os resíduos de construção e demolição (RCD) são um problema que deve ser considerado na conjuntura da sociedade, em razão das inúmeras consequências que acarretam na saúde humana e no meio ambiente em pequenas, médias e grandes cidades. Nesse cenário, podem ser destacados os desperdícios de materiais em obras de construção, a falta de processos de reaproveitamento e reciclagem de materiais, a obstrução de córregos e sistemas de esgotamento de águas, os impactos estéticos, os descartes clandestinos em áreas de preservação ambiental, os aterros e reaterros de áreas de forma descontrolada e o comércio clandestino, sem o devido licenciamento para armazenamento de resíduos (Bernardes, et al, 2008).

É certo que a tendência da redução da geração do RCD depende do desenvolvimento e aperfeiçoamento dos processos construtivos e tecnológicos, necessitando de maiores investimentos que envolvem custos e patamares de acesso à tecnologia, considerando então como limitada a redução citada (John, 2000).

Considera-se importante também, além da correta destinação, captação e processamento do RCD à nível de administração municipal, o gerenciamento articulado como todos envolvidos no processo: prefeitura, empresas construtoras, sociedade, órgãos fiscalizadores, etc.; esta correta articulação no gerenciamento é defendida em 2000 por Dorsthorst \& Hendriks, em que eles focam às ações articuladas durante todo o ciclo produtivo do RCD.

Para que se possa pensar na correta destinação dos resíduos sólidos da construção civil, é necessário, primeiramente, saber a quantidade de material que está sendo descartado, ou desperdiçado, para que a partir de então possa ser realizada uma análise de onde pode ser depositado esse material de forma a não prejudicar o meio ambiente, e em que pode ser reutilizado ou reciclado para voltar a ser utilizado.

Dessa forma, é preciso que a escolha da reciclagem de um resíduo seja criteriosa e pondere todas as alternativas possíveis, com relação ao consumo da energia e matéria-prima pelo processo de reciclagem escolhido, no caso do RCD gerado na cidade de Salgueiro, constata-se tipo de resíduo aproveitável, sendo processados em britadores ou utilizados em técnicas construtivas não convencionais, tendências em pesquisas acadêmicas na área de construção civil.

Diante disso, este trabalho busca fazer um levantamento inicial das quantidades de resíduos provenientes da construção civil na cidade de Salgueiro-PE em construções de médio porte, de forma que se possa avaliar os tipos de resíduos produzidos no canteiro de obras e quantificá-los com base na resolução do Conselho Nacional do Meio AmbienteCONAMA, n 307 de 2002, que aborda as 
diretrizes para a efetiva redução dos impactos ambientais gerados pelos resíduos oriundos da construção civil.

\section{Material e Métodos}

A presente pesquisa foi realizada no município de Salgueiro, localizada no sertão central do estado de Pernambuco, com uma população de mais de 60 mil habitantes, e tendo o cruzamento de duas principais BR's brasileiras, a BR 232 e a BR 116, a sua localização no mapa lhe permite a vantagem das pessoas participarem do processo de conurbação, ou seja, esse processo de ir e vim, de morar no município, acarreta as necessidades de mais edificações que possibilitem serviço público, seja ele a nível comercial ou residencial.

Um fato importante que deve ser ressalta é o crescimento populacional que refleti diversos problemas em torno do globo, segundo Hogan et.al. (p.90,2009) "muitos municípios passarão a enfrentar desafios para o abastecimento de água, bem como de coleta e tratamento de esgoto", estes que são resultados do crescimento populacional e das mudanças climáticas, ou seja, muitas cidades planejaramse para dar suporte a uma determinada população, porém a mesma sofre um processo de crescimento desordenado, que gera problemas de infraestrutura urbana.

Assim, quando crescem as construções, os resíduos gerados também crescem, fato que acontece no município de Salgueiro, logo, apresenta-se a forma da metodologia empregada nesse estudo:

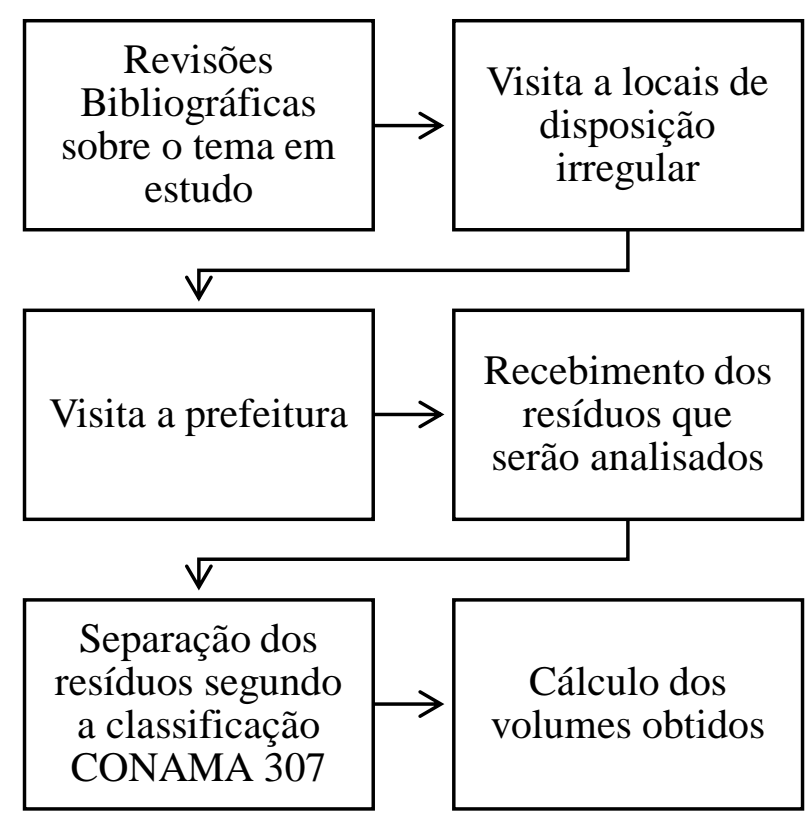

Figura 01: Fluxograma do método utilizado no estudo.

Diante do esquema apresentado, foi realizado uma revisão criteriosa no sentido de coletar aqueles trabalhos que tratem de problemas com características semelhantes ao tratado neste projeto. Posteriormente, foram realizadas visitas aos locais de disposição irregular dos resíduos da construção e demolição do município de Salgueiro/PE, identificando os problemas causados pela má gestão dos resíduos; assim como, visitas à secretaria de obras e serviços públicos do município para melhor entendimento da gestão municipal dos RCDs, para isto foi elaborado dois questionários distintos, onde constarão perguntas sobre os locais que a prefeitura reserva para acondicionamento dos RCDs, sobre a o plano de gerenciamento de resíduos sólidos urbanos, como são coletados e transportados o RCDs da cidade, entre outros questionamentos.

Foi feito o estudo dos RCDs gerado no município, para este estudo, a prefeitura disponibilizou 3 caçambas de $6 \mathrm{~m}^{3}$ cada para despejar o RCDs coletado no municio do Instituto Federal do Sertão PernambucanoCampus Salgueiro. Foi feita a separação do RCDs dos demais resíduos urbanos, e posteriormente a separação, quantificação e classificação do RCD de acordo com a norma do CONAMA 307/2002. 
(SÁ et al., 2015)

A classificação de acordo com norma toma como base os seguintes parâmetros: I - Classe A - são os resíduos reutilizáveis ou recicláveis como agregados, tais como: de construção, demolição, reformas e reparos de pavimentação e de outras obras de infraestrutura, inclusive solos provenientes de terraplanagem; de construção, demolição, reformas e reparos de edificações: componentes cerâmicos (tijolos, blocos, telhas, placas de revestimento etc.), argamassa e concreto; de processo de fabricação e/ou demolição de peças pré-moldadas em concreto (blocos, tubos, meiofios etc.) produzidas nos canteiros de obras; II - Classe B - são os resíduos recicláveis para outras destinações, tais como: plásticos, papel, papelão, metais, vidros, madeiras e gesso; III - Classe C - são os resíduos para os quais não foram desenvolvidas tecnologias ou aplicações economicamente viáveis que permitam a sua reciclagem ou recuperação; IV - Classe D: são resíduos perigosos oriundos do processo de construção, tais como tintas, solventes, óleos e outros ou aqueles contaminados ou prejudiciais à saúde oriundos de demolições, reformas e reparos de clínicas radiológicas, instalações industriais e outros, bem como telhas e demais objetos e materiais que contenham amianto ou outros produtos nocivos à saúde.

\section{Resultados e Discussão}

Dia 15 de outubro de 2014, no turno matutino, foi feita a primeira vista a Prefeitura Municipal de Salgueiro, na oportunidade foi feita uma entrevista, com base no questionário, com as secretarias de obras e serviços públicos do município. Na ocasião foi questionado sobre a realização da coleta e a destinação do RCD da cidade e das obras da própria prefeitura, observou-se que a secretaria de serviços públicos coleta o RCD depositado nas calçadas do município e os das obras da prefeitura, e destina a uma terreno particular emprestado, que o proprietário está aterrando este local com material trazido, da forma que é coletado, é despejado, sem uma seleção prévia do material.
Com relação ao total de resíduos coletados pela secretaria de serviços públicos, só no primeiro trimestre do ano de 2015 foi recolhido no município de Salgueiro, entre resíduos de construção e demolição com os resíduos sólidos, um total de 436,7 toneladas de resíduos no espaço urbano. Assim, temos que a geração já está em uma quantidade considerável, e a tendência é de aumento, o que indica que os resíduos analisados comprovam que a geração de resíduos pode ser contida em políticas sustentáveis, como o reaproveitamento de pavimentação, e a reciclagem.

Foi questionada também sobre a existência de um local onde a população pudesse depositar o entulho de suas construções, assim como os caçambeiros e empresas de recolhimento de entulho, a prefeitura não disponibiliza este local, então a população faz esse descarte de forma ilegal em terrenos privados e públicos, a exemplo da Estação Forró (Figura 02).

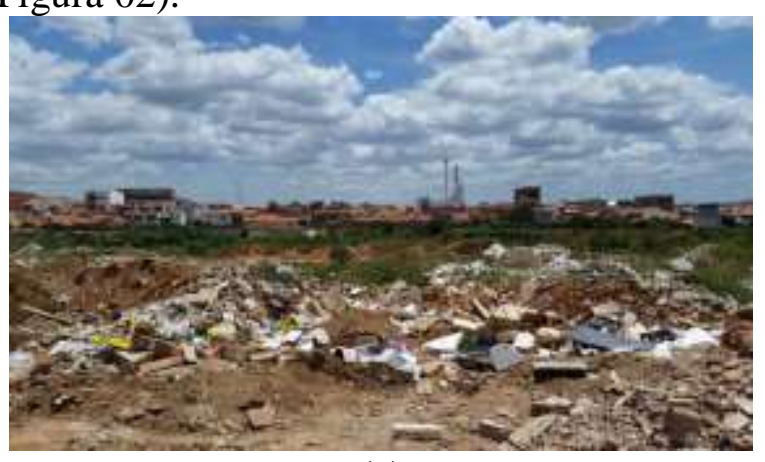

(a)

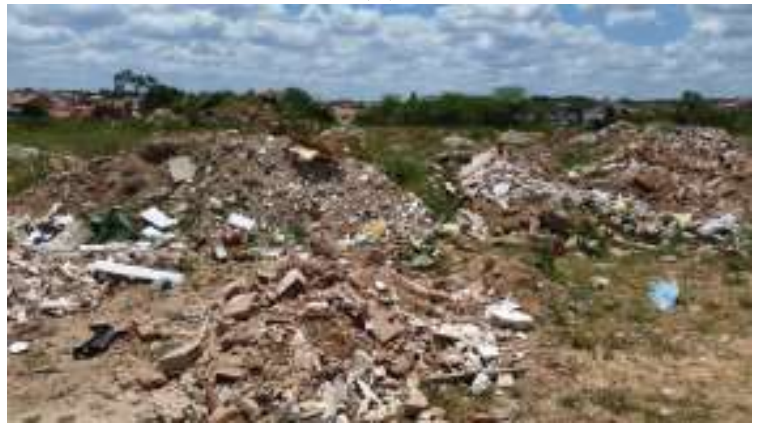

(b)

Figura 02: Deposição irregular de RCD, Estação Forró em Salgueiro (a) e (b)/PE Foto: Eduardo Teixeira

Em visita realizada a Estação Forró, observou-se uma grande quantidade de RCDs depositado de forma irregular e ilegalmente, juntamente com lixo urbano. Pode-se notar também que latas de tintas usadas, estavam cheias de água da chuva, podendo vir a ser um 
(SÁ et al., 2015)

foco de dengue. O terreno em questão é bem próximo ao centro da cidade, e cercado de bairros residenciais, trazendo problemas para o bem estar da população circunvizinhas. Dentre estes resíduos, foram escolhidos uma parcela a ser transportada pela prefeitura para o Instituto Federal do Sertão Pernambucano- Campus Salgueiro (Figura 02). Após o recebimento foi feita uma pré seleção do material (Figura 03).

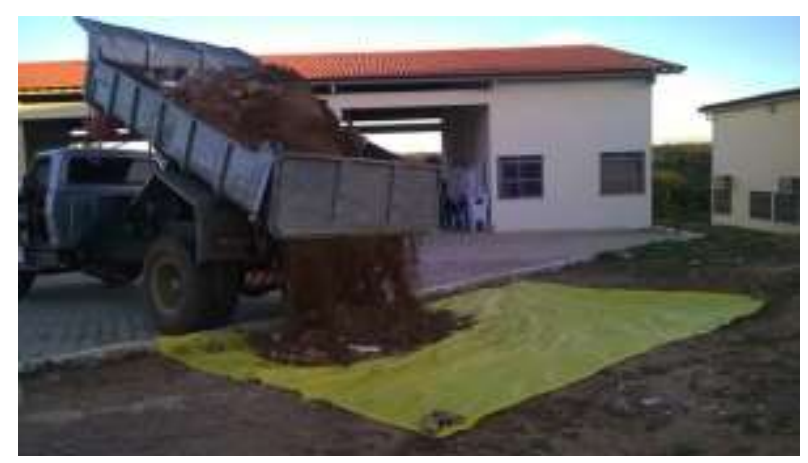

(a)

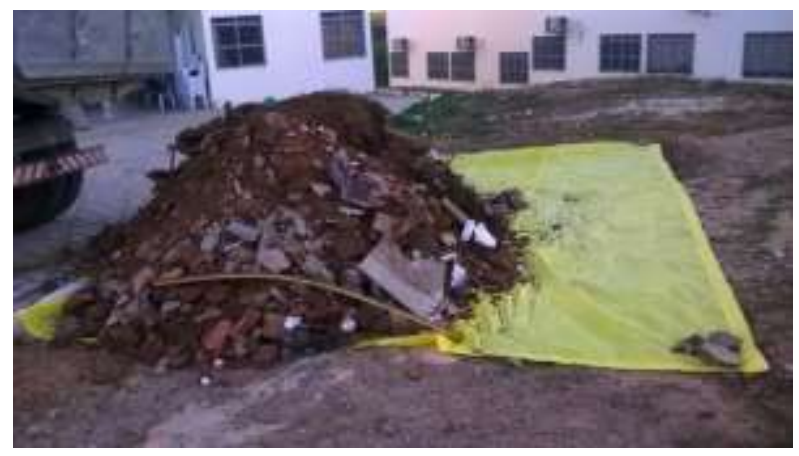

(b)

Figura 03:Recebimento de RCD's (a) e (b)/Foto: Maria do Socorro

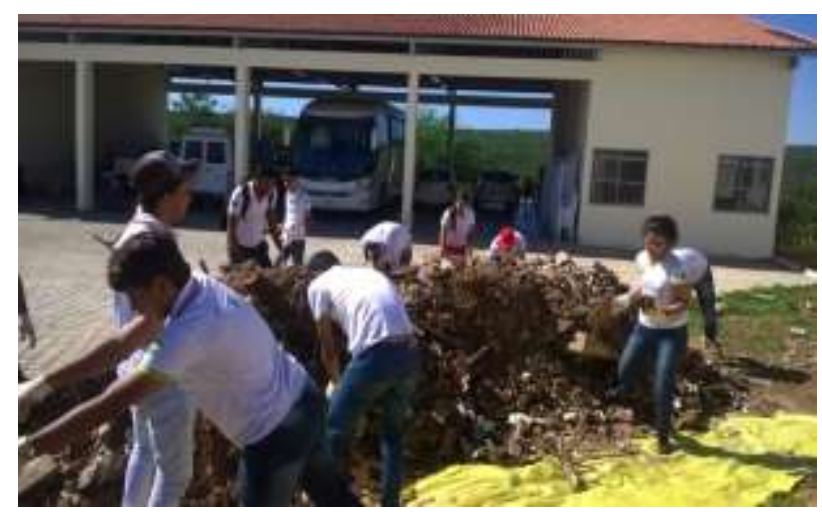

Figura 04: Separação de RCD’s para Classificação/Foto: Maria do Socorro
Foram analisados os resíduos de construção e demolição, depositado no IF Sertão PE, Campus Salgueiro, sendo feita uma separação dos resíduos realizada com alunos do curso técnico em edificações que concordaram em ajudar no estudo, e após a seleção foram observados os valores descritos na tabela 01 . Para quantificação do material foram utilizados recipientes, na qual foram calculados os respectivos volumes para o volume total de cada classe. Dos, aproximadamente, $18 \mathrm{~m}^{3}$ de entulho que a prefeitura disponibilizou, a grande parte era solo com resto de raízes, plantas, e poda de árvores. A quantidade de resíduo analisado foi de uma amostra de aproximadamente $2 \mathrm{~m}^{3}$, visto que o restante não eram resíduos da construção.

\begin{tabular}{|l|l|}
\hline \multicolumn{2}{|c|}{$\begin{array}{c}\text { Quantificação dos Resíduos de Construção } \\
\text { e demolição }\end{array}$} \\
\hline $\begin{array}{l}\text { Classe A volume em } \\
\mathrm{m}^{3}\end{array}$ & $\begin{array}{l}\text { Classe B volume em } \\
\mathrm{m}^{3}\end{array}$ \\
\hline Recipiente $1=0,239$ & Recipiente $1=0,073$ \\
\hline Recipiente $2=0,239$ & Recipiente $2=0,073$ \\
\hline Recipiente 3=0,237 & Recipiente $3=0,073$ \\
\hline Recipiente 4 $=0,237$ & Recipiente $4=0,073$ \\
\hline Recipiente 5=0,237 & Recipiente 5=0,073 \\
\hline Total: $0,952 \mathrm{~m}^{3}$ & Recipiente $6=0,073$ \\
\hline
\end{tabular}

Tabela 01: Quantificação do RCD

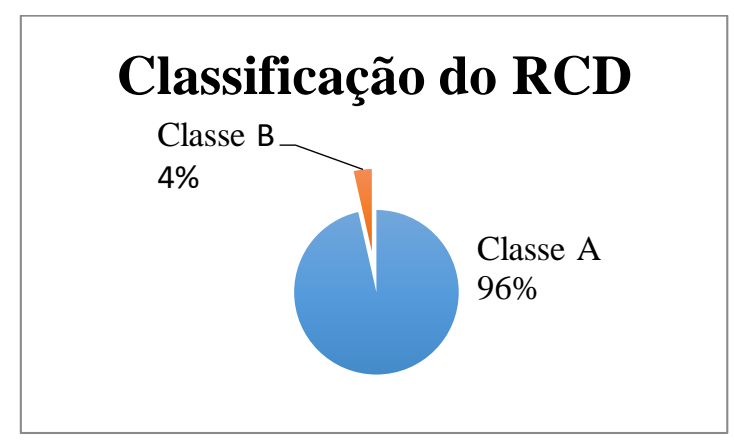

Figura 05:Classificação dos resíduos analisados

Observa-se que do montante que foi identificado com RCD (representação na figura 05 ), apenas $4 \%$ era resíduo da classe B, que são resíduos que podem ser reciclados para outra destinação que não seja como agregado, os outros $96 \%$ é resíduo de classe A, que podem ser britados e voltar a obra como agregados, com isso possibilita uma redução de novos materiais, 
(SÁ et al., 2015)

diminuindo os resíduos que são despejados em locais não apropriados, e prejudicando o meio ambiente. Ressalta-se que a parte identificada como Classes $\mathrm{C}$ e $\mathrm{D}$ foi tão pequena que não resultou em nem $0,5 \%$ do total, por isto foi descartada das discussões.

\section{Conclusões}

Analisando os resultados obtidos neste trabalho, observou-se, durante a entrevista com as secretarias de obras e serviços públicos que, nas obras executadas pela prefeitura, não são tomadas nenhuma medida para redução ou a não geração dos resíduos da construção e demolição. O município ainda não possui um local adequado para disposição do resíduo, deixando um material que poderia ser beneficiado e reutilizado como material de construção em local inapropriado, impossibilitando o reuso e a reciclagem.

O município já sofre as consequências desse descarte irregular, na Estação Forró observou-se entre os resíduos latas vazias de tinta que contem contaminantes, prejudicando o solo e o lençol freático do local, além de acumular água e com isso ser um foco de dengue. A Estação Forró fica bem próximo ao centro do município, e rodeado de casas.

Conclui-se também que grande parte dos resíduos de construção do local é da classe A, que podem ser beneficiados, britados e voltar como insumo na construção civil. Assim, sugere-se a prefeitura, a criação de um "aterro seco", que seria um local onde a população, os caçambeiros, e empresas de entulho levaria o resíduo, estes seriam separados de acordo com a classe, e os de classe A seriam britados, como brita e areia, e poderiam serem utilizados nas próprias obras do município. Isto beneficiaria tanto a população, que não sofreia mais com as consequências da disposição incorreta, a prefeitura que economizaria na compra de materiais de construção para as obras, e principalmente, o meio ambiente.

A prefeitura se mostrou preocupada com o problema dos resíduos da cidade, e interessados nos resultados deste projeto. As secretarias de Obra e de serviços públicos do município foram muito acessíveis e auxiliaram muito para a obtenção dos resultados do projeto.

Constatou-se também a falta de ações conjuntas com outros setores interessados, como empresas construtoras, sociedade civil, órgãos ambientais, comunidade acadêmica local.

\section{Agradecimentos}

A toda equipe da Coordenação de Pesquisa, Inovação e Pós Graduação do Instituto federal de Educação, Ciência e Tecnologia do Sertão Pernambucano - Campus Salgueiro, especialmente a Professora e Coordenadora desta respectiva pesquisa, Camila Macedo Madeiros e a secretaria de serviços públicos do município de Salgueiro, Senhora Gorete Coelho.

\section{Referências}

BERNARDES, A.; THOMÉ, A.; PRIETTO, P. D. M.; ABREU, A. G.; Quantificação e classificação dos resíduos da construção e demolição coletados no município de Passo Fundo, RS. Ambiente Construído. Porto Alegre: 2008.

CARVALHO, P. M.; Gerenciamento de resíduos de construção civil e sustentabilidade em canteiros de obras de Aracaju. Dissertação de Mestrado. Universidade Federal de Sergipe. São Cristóvão: 2008.

$\begin{array}{ccr}\text { CONSELHO NACIONAL DO MEIO } \\ \text { AMBIENTE. } & \text { Disponível } & \text { em: }\end{array}$ http://www.mma.gov.br/port/conama/index.cfm . Acesso: Fevereiro/2014.

DORSTHORST, B.J.H; HENDRIKS, Ch. F. Reuse of construction and demolition waste in the EU. In: CIB Symposium: Construction and Environment - theory into practice. São Paulo, 2000. Proceedings. São Paulo, EPUSP, 2000.

ESTEVÃO, R.; MEIRA, A. R.; ARAÚJO, N. M. C.; Análise quantitativa dos resíduos da construção civil: um estudo de caso. VII Congresso Norte-Nordeste de Pesquisa e Inovação. Palmas-TO: 2012. 
(SÁ et al., 2015)

JOHN, V.M. Reciclagem de resíduos na construção civil - contribuição à metodologia de pesquisa e desenvolvimento. São Paulo, 2000. 102p. Tese (livre docência) - Escola Politécnica, Universidade de São Paulo.

PREFEITURA MUNICIPAL DE SAGUEIROPE. Disponível em: http://www.salgueiro.pe.gov.br/ noticias_2013/20130327_not01.htm. Acesso: Fevereiro/2014.

REVISTA ZUM. Disponível em: http://revistazum.com.br/radar/brasil-oespetaculo-do-crescimento/.

Acesso: Fevereiro/2014.

SINDICATO DA INDÚSTRIA DA CONSTRUÇÃO CIVIL DO ESTADO DE SÃO PAULO. Gestão Ambiental de Resíduos da

Construção Civil: A experiência do SindusCon-SP. SindusCon-SP. São Paulo: 2005.

HOGAN, Daniel Joseph; MARANDOLA JR, Marandola Junior; OJIMA, Ricardo. População e ambiente: desafios à sustentabilidade. 2009. 